\title{
Gran Chaco, percepciones de la imagen
}

\author{
Gran Chaco, percepções da imagen
}

Gran Chaco, image perceptions

\author{
Belén Azarola
}

Palabras clave:

Grete Stern

Fotografía

Antropología

\section{Resumen:}

En el presente trabajo me propongo indagar sobre las percepciones de diversos actores sobre la serie "Aborígenes del gran Chaco" de la fotógrafa Grete Stern, haciendo puerto en una categoría en uso del campo registrado, la estética. Buscaré asimismo reflexionar sobre el lugar que estos actores asignan a la serie en la totalidad de la producción artística de Stern dando cuenta, a lo largo del recorrido, de ciertas cuestiones de la subjetividad de la artista que resultan significativas. Para ello, tomaré en cuenta algunas particularidades históricas que permiten situar esta producción en un contexto más dilatado, el de la fotografía de comunidades indígenas en la Argentina, reconociendo ciertas rupturas con modos anteriores de fotografiar al indígena. Metodológicamente, el trabajo se basa en la investigación etnográfica con observación participante, el registro de conversaciones informales así como de entrevistas semi-estructuradas realizadas en múltiples puntos de la ciudad de Buenos Aires a lo largo de cuatro meses. 


\section{Resumo:}

No presente trabalho me proponho a investigar as percepções de diferentes atores sobre a série "Aborígines do Gran Chaco" da fotógrafa Grete Stern, fazendo porto em uma categoría em uso no campo do registro, a estética. Procurarei, também, refletir sobre o lugar que esses atores atribuem à série na totalidade da produção artística de Stern dando conta, ao longo do percurso, de certas questões da subjetividade da artista que são significativas. Para fazer isto, terei em conta algumas particularidades históricas que permitem colocar essa produção em um contexto mais amplo, o da fotografia de comunidades indígenas na Argentina, reconhecendo certas rupturas com modos anteriores de fotografar o índio. Metodologicamente, o trabalho é baseado na pesquisa etnográfica com observação participante, no registro de conversas informais bem como de entrevistas semi-estruturadas realizadas em múltiplas partes da cidade de Buenos Aires ao longo de quatro meses.

Palavras chave:

Grete Stern

Fotografia

Antropologia

\section{Keywords:}

\section{Grete Stern}

Photography

Anthropology

\section{Abstract:}

This paper presents an inquiri into the insights of the various agents involved in the series "Aborígenes del Gran Chaco" of the photographer Grete Stern, focusing on the fixed field of aesthetics. It contemplates the place this series has in the entirety of Stern's artistic production covering certain aspects of the artist's subjectivity that prove important. By taking into account historical specificities, the production is able to fit in the broader field of photography of native Argentine communities, revealing a break from older ways of photographing the aborigine. This paper is rooted in ethnographic study with participant observation, recording casual conversations as well as semi-structured interviews conducted in various spots of the city of Buenos Aires during a four month period. 
Gran Chaco, percepciones de la imagen

\section{Introducción}

En este trabajo busco reflexionar sobre las percepciones de diversos actores sobre la serie "Aborígenes del gran Chaco" de la fotógrafa Grete Stern, haciendo puerto en una categoría en uso del campo registrado, la estética. Buscaré asimismo reflexionar sobre el lugar que estos actores asignan a la serie en la totalidad de la producción artística de Stern dando cuenta, a lo largo del recorrido, de ciertas cuestiones de la subjetividad de la artista que resultan significativas. Para ello, tomaré en cuenta algunas particularidades históricas que permiten situar esta producción en un contexto más dilatado, el de la fotografía de comunidades indígenas en la Argentina, reconociendo ciertas rupturas con modos anteriores de fotografiar al indígena. Metodológicamente, el trabajo se basa en la investigación etnográfica con observación participante, el registro de conversaciones informales así como de entrevistas semi-estructuradas realizadas en múltiples puntos de la ciudad de Buenos Aires a lo largo de cuatro meses. Con el propósito de situar a los interlocutores en el contexto particular de los acontecimientos contaba con fotografías de la serie durante las entrevistas, apelando al poder de traer a la memoria que las imágenes poseen, convocando a un desarrollo en diálogo con ellas y a hacer surgir cuestiones que interpelan al recuerdo.

Ineludiblemente, a partir del momento en que uno hace explícito su interés y lo diagrama en los términos de una pregunta de investigación, se encuentra ante la relación dual que esto supone, la de la apertura y el límite (GADAMER, 1993, p. 441). Habrá, entonces, aspectos de la cuestión que serán contemplados y otros desechados en función de su relación con el objetivo planteado anteriormente. Me propongo ir recorriendo de manera cronológica el proceso de indagación (con sus planteamientos y reformulaciones) realizado hasta el momento, a la luz de la información y los datos generados a partir de diversas fuentes. Los distintos actores convocados fueron elegidos en función de la pertinencia de sus intervenciones. Fue entrevistada en primer lugar una de las directoras de la Galería Vasari, seguida de la directora actual de curaduría y programación de la Fundación Proa y, por último, un especialista de la obra de Stern además de su principal biógrafo, Luis Priamo.

\section{Sobre "Aborígenes del Gran Chaco"}

Antes de abocarnos a dicha tarea, resulta pertinente realizar una breve caracterización de la serie "Aborígenes del gran Chaco", la cual se compone de cerca de mil quinientas tomas cuyas películas se encuentran en formato $6 \times 6 \mathrm{~cm}$ y $35 \mathrm{~mm}$. Se trata, en su mayoría, de fotografías formato grande y en blanco y negro en las que Stern fotografía una cantidad de aspectos diversos del cotidiano de las comunidades indígenas chaqueñas. Existen además, algunos componentes que hacen al contexto de producción que tienen hoy consecuencias en la serie tal y como se nos presenta hoy. En primer lugar, el hecho de que Grete Stern no haya revelado las fotografías durante el viaje, lo cual se traduce en la imposibilidad de rehacer tomas. El corto plazo que permanecía en cada sitio en el que fotografiaba está estrechamente ligado a la rapidez necesaria para la toma de decisiones técnicas y creativas. Tercero, Grete detestaba, en palabras de Priamo, "la pose" en general, lo mismo que la "pose artística", y por último, el no menos importante hecho de que hubiera tomado la gran mayoría de las fotografías en formato grande. Una cámara $35 \mathrm{~mm}$ supone mayor versatilidad, es portable, per- 
mite fácilmente la fotografía instantánea. Por su parte, el formato $6 \times 6 \mathrm{~cm}$ implicaba una cámara de mayor complejidad, con la imagen invertida, donde todo lo que estuviera ubicado a la derecha se situaba a la izquierda y viceversa; su mayor tamaño obligaba además a la utilización de un trípode. Es por eso que siempre que se le imposibilitó la utilización de este último instrumento, Grete fotografió situando la cámara en su estómago. Gracias a la información que brinda Luis Priamo acerca de la categorización que realiza Stern en 1963 ante el Fondo Nacional de las Artes sobre lo que tenía intención de fotografiar en el Chaco argentino, con motivo de un pedido de subsidio, identificamos la siguiente enumeración:

1. Paisaje donde viven. 2. Tipo de vivienda y su construcción. 3. Vestimenta. 4. Normas de vida, higiene, costumbres alimenticias, etc. 5. Aspecto fisionómico. 6. Expresiones de artesanía: materia prima, producción, manufactura, distribución del trabajo, etc. (PRIAMO et al., 2005, p. 38)

Grete Stern ya había viajado al Chaco en dos oportunidades previo a 1963. La primer oportunidad resultó como fruto de la convocatoria de la Universidad Nacional del Nordeste en 1958 para que la fotógrafa realizara tomas sobre las comunidades indígenas de la región, con miras a la realización de un futuro museo y archivo de la Escuela de Humanidades. La segunda, desde el '59 al '60 para formar parte de los talleres de arte regional de la misma universidadii, conjunto con su contemporáneo Clément Moreauiii. Una vez conseguido el subsidio, viajó en 1964 al Chaco, donde incluso consideró una mayor apertura de los pueblos que había considerado fotografiar a priori, abarcando entonces comunidades toba, mocoví, pilagá, chorote, chané, curupí y wichi. El corpus de fotografías de los primeros dos viajes como, asimismo, gran parte de las que componen el del 64, se encuentra hoy en manos del coleccionista Matteo Goretti, constituyéndose de este modo el campo de comercialización del arte como el foco primero de mi mirada.

\section{Etnografía de las percepciones}

Antes de dar comienzo al recorrido sobre las múltiples perspectivas de los sujetos, las prácticas de investigación implicadas conjunto con mi propia subjetividad como estudiante de antropología (ROCKWELL, 2009), creo necesario algunos comentarios preliminares. Sin dudas, la condición de investigadora (para el caso, investigadora-estudiante) condiciona toda práctica de recorte del campo, decisiones metodológicas respecto al abordaje del problema planteado, su reformulación, y la interacción con todo sujeto convocado. Todo sujeto que prevea y presuponga de antemano el devenir del encuentro, como también sucede momento a momento durante la interacción, puede elegir situarse privilegiando determinado atributo que quiera volver visible de su persona, significándose y resignificándose en el devenir, estrechamente vinculado a la violencia simbólica a la que refería Bourdieu (1999, p. 528).

La Galería Vasari comercializaba la obra de Grete Stern en el país y sigue representándola en el exterior, promoviéndose además como uno de los componentes principales que Ilevaron al ámbito del arte argentino a considerar la fotografía como arte. Se encuentra ubicada en el centro de la ciudad de Buenos Aires sobre la calle Esmeralda y posee una cartera de artistas entre cuyos nombres encontramos asimismo el de Annemarie Heinrich, y sus hijos, Alicia y Ricardo Sanguinetti, quienes hoy cuentan con el Estudio Heinrich-Sanguinetti sobre la calle Callao. Está dirigida por dos directoras, con quienes me contacté en primera instancia sobre la base del problema de investigación planteado 
en un inicio. El propósito de la indagación se centraba en la exploración de las representaciones que actores, participantes de distintos niveles de la comercialización de la obra de la fotógrafa GreteStern, fueron construyendo con el tiempo sobre la población indígena de la serie "Aborígenes del gran Chaco". En aquel momento, presuponía el valor mercantil para aquel sector y la vigencia del "exotismo" sobre la idea de indígena, elemento, este último, que deseché en la medida en que reformulaba mis preguntas de investigación.

Durante esta instancia, me preguntaba sobre los sentidos y significaciones que quieres pertenecen al ámbito privado del arte en Buenos Aires, construyen en torno a la serie. Intenté explorar qué idea de la Argentina tenían desde la galería, cuáles eran las representaciones que se hacían sobre Buenos Aires. Estaba interesada por el modo de comercialización, el público al que estaría dirigida la venta, la manera en que la serie era presentada y la posición de las directoras de la Galería Vasari frente a la serie. Finalmente, profundicé solamente en el punto de vista de las directoras en relación a sus percepciones, obligándome a reevaluar la pertinencia de mi objetivo centrado en la reflexión sobre las formas de representación de la nación y su diversidad étnica interna, sobre la base de la comercialización de la serie fotografía "Aborígenes del gran Chaco". No sería hasta después de la entrevista que tuvimos que comprendería la importancia de reflexionar sobre las representaciones de nación, entendiéndolo como uno de los elementos a desarrollar, considerando también la marginalidad y la estética. Resulta fundamental señalar que fue, sin embargo, la problematización de la noción de estética la que me permitió dar cuenta de una manera más encarnada en los sujetos ciertas divergencias y continuidades. Su relevancia se centra en la influencia que ésta noción ejerce en la construcción de sentidos y valores locales en lo referente a la serie y, a raíz de esto, establecí una definición provisoria de estética que, el recorrido de las situaciones particulares registradas y la mirada sobre la puesta en diálogo de los sujetos con la serie, permitió ir complejizando al concebir la categoría en uso.

Entenderé, entonces, la estética como una experiencia que toca al sujeto, lo alcanza desde lo sensible y que se encuentra en vinculación con la noción de lo bello. Etimológicamente, hablamos de un neologismo cuyo origen se identifica con el griego, con las palabras aisthesis que nos remite a la sensación, la sensibilidad y el sentimiento, a aistheton y lo sensible, y al adjetivo aisthetikos significando aquello que puede ser percibido por los sentidos (SAUVANET, 2004, p. 6). Retomar la procedencia de la palabra, lejos de intentar una cristalización del término, invita a conocer acepciones cuyo denominador común se centra en el campo de lo sensible. Es ineludible, entonces, la función estética de la imagen en tanto desencadenante de sensaciones específicas en el espectador, ya se trate del público que acceda a la serie como de la invocación de esta función en tanto estrategia metodológica (como en este caso).

Conversando sobre la serie con una de las directoras de la galería, ella aludía al desinterés de la gente en cuanto a considerar la serie Aborígenes como atractiva de ser comprada, y lo justificaba alegando que "estéticamente" no era lo que se buscaba, podríamos decir, en términos comerciales. Sí nombró la serie Sueños (fotomontajes de Stern que han tenido amplia difusión, anteriores las fotografías en el Gran Chaco), que Constantiniv compró para su colección, o la exhibición que parece encontrarse en la programación 2015 del MOMA ${ }^{v}$ en la que se mostrará esta misma serie de corte psicoanalítico. Reconociendo la serie sobre aborígenes como "fabulosa", distinguía la importancia que ésta podía tener para el campo de la 
antropología en discrepancia con la reducida significación con la que cuenta para otros campos, que no delimitó pero, en el que refiriéndose a esos "otros" incluyó un "nosotros", que lleva a pensar en el ámbito de venta de arte, del que ella forma parte. Desde esta distinción que marca, comencé a reconocer que la serie es considerada, en gran medida, como de un fuerte tinte etnográfico, lo que pareciera oscurecer de algún modo la serie para lo que parece establecerse como el campo de la fotografía. El acento siempre posado sobre la serie Sueños era una constante cuando hablábamos de la obra de Stern, marcando claramente un interés privilegiado por aquella porción de la producción artística, 'su obra sobre indígenas no es tan valorado como su otro trabajo, pero era lo que más le gustaba a ella [Grete], eso y los retratos'. Resulta evidente que la directora reconocía un fuerte componente emocional de la artista frente a esta serie particular.

Si bien la serie no parecía contar con un lugar destacado en lo relativo a la venta de obras de arte, algo habría notado la Fundación Proa para elegirla como parte de la programación prevista para el año 2005; institución interesada fundamentalmente en el arte contemporáneo internacional. Para no acotar el abordaje a un solo ámbito y ampliarlo en un contexto de significaciones más dilatado, busqué inscribirlo en el campo de la circulación y la exhibición, considerando la apertura del campo hacia los sentidos que le eran asignados a la serie en las percepciones de los sujetos de la Fundación Proa. La exhibición titulada "Culturas del gran Chaco" tuvo lugar desde abril hasta finales de mayo de aquel año y conjugaba 95 fotografías de Grete Stern, tomadas entre 1958 y 1964 en el Chaco argentino, con objetos del Museo Etnográfico de la Universidad de Buenos Aires, Juan B. Ambrosetti. Los curadores fueron Luis Priamo para las fotografías y José A. Pérez Gollán para los objetos del museo, quienes además estaban a cargo de los escritos de dos secciones del libro que funcionó a modo de catálogo de exhibición. Este fue editado el mismo año por la Fundación Antorchas y la Fundación C.E.P.P.A., siendo Priamo quien seleccionó las tomas que conformarían el corpus fotográfico $\mathrm{y}$, al mismo tiempo, quien escribió sobre "Grete Stern y los paisanos del Gran Chaco". Fue Gollán, por su parte, quien se encargó de desarrollar lo referente a la "Población indígena del actual territorio argentino". También incluye un escrito de Pablo Wright sobre "Los indígenas del Chaco argentino" y un relato de viaje redactado porStern con motivo de acompañar sus fotografías durante la exhibición en la Universidad Nacional de La Plata hacia 1971.

Al ser "Culturas del gran Chaco" la última muestra que se realizó de la serie hasta el momento, se me presentó como un camino posible para indagar sobre las percepciones que tienen sobre ella actores vinculados al campo de la exhibición. Fue así que busqué ponerme en contacto con quien hoy estuviera a cargo del área de programación o de documentación en la Fundación y di con Cintia, directora de programación y curaduría. Fue ella quien, con mucha amabilidad y buena predisposición, me acercó a los marcos en los que se hacía posible la presencia de las fotografías sobre las comunidades indígenas chaqueñas de Grete en la Fundación Proa, si bien no era directora durante el 2005. Otorgó, asimismo, una nueva mirada para pensar las fotografías y el terreno de la estética.

Mi encuentro con la directora de programación y curaduría de Proa, un jueves de finales de octubre en la Fundación al comienzo de "El caminito" en el barrio La Boca frente al riachuelo, puso de manifiesto, de un modo más evidente que en otros casos, 'la contractualidad en el seno de la práctica etnográfica', en palabras del antropólogo francés Marc Abélès (2002, p. 46). Al pedirle su colaboración en tanto directo- 
ra para la realización del presente proyecto, me concedió su participación y, luego, pidió una devolución del trabajo para el archivo de la Fundación Proa. Este hecho, permite reflexionar sobre las negociaciones implícitas en toda interacción, donde se acuerdan de forma más o menos equilibrada las condiciones que hacen posible el acceso a determinado campo, poniendo de relieve también la dimensión ética.

Cada dos o tres años se realizan muestras que vinculan arte con antropología, arqueología y temáticas que abarcaran "otras culturas", me comentaba la directora de programación, caracterizando así el marco en que se inscribía "Culturas del gran Chaco". Vale aclarar, que todas las exhibiciones son temporales ya que no cuentan con un "patrimonio, una colección" y que para la realización de estas empresas, enfatizaba, concedían gran valor a "convocar referentes", personas especializadas, en oposición a otros museos que parecieran "colonizar los temas". Mientras hablábamos con algunas de las fotografías desplegadas sobre la mesa me preguntaba qué sería lo que querrían mostrar al público que visitara aquellas salas, qué pensaría ella(si bien no era la directora del área de programación durante el 2005) que se intentaba rescatar. Las dos tomas que le presenté para indagar sobre ese aspecto eran las que aparecen en los dos espacios de divulgación virtual donde encontramos información sobre la exhibición. Una de ellas, el retrato a una mujer toba de perfil, presenta las fotografías en el sitio web; la otra aparece en la gacetilla que detallaba la inauguración y las características de la muestra con dos niñas en campos de algodón. A Cintia le remitía a "traer algo de la juventud, la niñez, como mostrando que sin importar las diferencias culturales, tienen un rostro similar". Hablaba de "la otra Grete", contrapuesta a "la de la vanguardia", ya demasiado explotada. Esta dicotomía que introducía servía para explicar el "vuelco" que veía expresarse a partir de la serie, como una ruptura sin retorno ligada a que la artista se hubiera encontrado con "un tejido social, emocional" con el cual se involucró y comprometió. De alguna manera, su apreciación parecía mostrar el modo en que concibe un quiebre dado en la trayectoria de Grete, o más aún en su propuesta artística, como un aspecto novedoso a ser mostrado al público, una nueva lectura.

La "estetización" de ciertos fenómenos a través de la fotografía en blanco y negro, se relacionaba para la directora con la propuesta de Grete en la serie "Aborígenes del gran Chaco". A modo de ejemplo $\mathrm{y}$, simultáneamente, como una forma de establecer un punto de comparación con otro artista que pasó por las salas de exhibición de la Fundación Proa, nombró a Sebastián Salgado. La propuesta de este último artista, contaba, se centraba en mostrar el trabajo infantil, la explotación, las diásporas, hizo una pausa, y continuó diciendo: "es espeluznantemente bello". Lo relacionaba con una 'estética del horror, la desigualdad, la marginalidad'. No obstante, la serie de Grete Stern no se establecía, a su modo de ver, como una propuesta tan "chocante" como la de Salgado, pero seguiría cierta línea de similitud, introduciendo la idea de 'sacá la foto o andá a ayudarlos'. Diría que la directora de este área de Proa manifestaba el papel de apelar a la belleza en las propuestas artísticas como un modo de poner en relieve realidades subalternas, creando también el paralelismo con Juanito y Ramona de Antonio Bernivi.

Revisando el contexto más amplio en que se inscribe la serie en la fotografía sobre indígenas en la Argentina, registramos que ya comenzaban las primeras expresiones contra la exclusión de los pueblos indígenas en los años '30; numerosos fotógrafos de postales denunciarían la explotación y prostitución de indígenas en ingenios azucareros (MASOTTA, 
2008, p. 92). Se caracteriza a aquellos fotógrafos que de algún modo visibilizaron sectores marginales como críticos de la realidad social y mensajeros reivindicaciones sociales. Posteriormente, esto pasó a caracterizar a la "fotografía social", de la cual Grete Stern y la antropóloga francoestadounidense Anne Chapman se rememoran como exponentes (PRIAMO et al., 2012, p. 10). En la serie "Aborígenes del gran Chaco", podemos ver una clara ruptura con modos anteriores de fotografiar a los indígenas, métodos que consistían en recrear los aspectos a los que se asociaba a estos pueblos (en el caso de que el fotógrafo los identificara como faltantes en la realidad). Estos modos consistían en:

\begin{abstract}
Expulsar de la escena fotográfica toda marca de modernidad, elegir 'telones de fondo' rústicos o naturales, hacer posar a los sujetos con objetos rústicos (arcos, flechas, palos u otros), desnudar el cuerpo indígena, una vez compuesta la escena, hacer posar al indígena pasivamente (por lo general parado frente al objetivo). (MASOTTA, 2008, p. 129)
\end{abstract}

Podemos, además, contraponer la propuesta de Grete Stern al enunciado anterior en los términos en que Luis Priamo describía el rechazo por parte de la artista de la pose, y sobre todo de "la pose artística” ya nombrada. Retomando, por otro lado, la analogía que establecía la directora de programación y curaduría en relación a la representación del marginado desde el campo del arte, el mismo Berni, desde las artes plásticas, comenzaba en la década del '60 la famosa serie de collages cuyas figuras protagonistas, Juanito Laguna y Ramona Montiel, mostraban, a modo de narración inventada por el propio artista, lo que sucedía en las villas miseria vii.

Con el objetivo de seguir indagando en los criterios de selección de fotografías para el libro Aborígenes del Gran Chaco.
Fotografías de Grete Stern: 1958 - 1964 / seleccionadas por Luis Priamo, que constituye la más completa fuente de consulta de la serie, Luis Priamo me citó en su casa, cerca de Boedo. El encuentro fue el resultado de haberme contactado con él para pedirle su participación, sus puntos de vista, lo mismo que el acceso a un costado más privado de Grete que él pudiese brindarme. Mientras calentaba agua para compartir unos mates me contaba que Grete "curó las fotografías etnográficamente", y no ameritaba hacer un libro de esa naturaleza. En tanto especialista de la obra, tuvo un papel fundamental en la producción del libro, como ya el título lo anticipa, al cual hacía referencia cuando hablaba de la curación de las imágenes. Fue a partir de un coleccionista que cuenta tenían en común con Grete Stern, Jorge Helf, que entran en contacto con ella por primera vez en 1992. Por aquel momento, Luis estaba a cargo de un programa de conservación de fotografías en la Fundación Antorchas y la artista necesitaba colaboración para ordenar su archivo, de modo que la ayudó y se mantuvieron en contacto.

En lo que a la serie refiere, Grete seleccionaba sobre todo fotografías sobre artesanías, "más didácticas que expositivas". La selección para el libro fue realizada sobre la colección privada de Matteo Goretti, utilizando los contactos para aquella tarea, sobre la base de cerca de 800 imágenes, donde la misma Grete había agrupado distintas fotografías. Argüía haber buscado la manera de mostrar equilibradamente lo que Grete había querido mostrar, y enumeró "personas, rostros, costumbres, hábitat, artesanía". Emprender la curación del material dice hacer sido una tarea difícil, ya que para Luis el desafío parecía presentarse en cuanto a que la curación etnográfica de Grete no sería la curación que él mantendría para la edición del libro. Para este fin, decidió un relato cronológico del viaje, 'introduciendo de algún modo a Grete'. Decidió mostrar asimismo 
fotografías que no habían sido seleccionadas por la artista, artesanías terminadas, a color, lo mismo que otras fotografías como el primer plano del rostro de una mujer con tatuajes bajo los ojos que, posiblemente, pasarían desapercibidos en una fotografía en blanco y negro. El propósito de este conjunto era poder darle 'más información al lector con interés fotográfico'. Reconocemos en esta distinción una cierta continuidad con la percepción de la directora de la Galería Vasari sobre las diferencias entre lo que podría ser atractivo para el campo de la antropología en contraposición al de la fotografía. Curiosamente, nadie nombraba la significancia que podría tener el corpus de información relevado por Stern entre las comunidades indígenas chaqueñas para todos aquellos que quisieran aprender sobre técnicas y saberes de artesanías de los grupos humanos fotografiados, que podrían venir desde el terreno de las artes plásticas, por ejemplo, no solamente desde la antropología.

Para Priamo, la serie "Aborígenes del gran Chaco" se presenta en concordancia con los "principios éticos y artísticos" de la fotógrafa, anclados fundamentalmente en su formación en la Bauhaus donde la cuestión social contaba con una importancia significativa. Se paró de la silla en la que estaba sentado para buscar una caja azul en el armario que se hallaba detrás suyo, rotulada con el nombre de Grete Stern, de la que sacó un recorte con la leyenda "Exposición de fotografías de Horacio Coppola y Grete Stern"; 'esto está en el libro', me dijo extendiéndome la bolsita transparente en la que se encontraba el recorte. Seguido, lo agarró y leyó en voz alta aquella presentación de exhibición que se realizó en Sur hacia 1935. Se distinguían dos momentos para la conformación de la imagen fotográfica, "la preparación de la toma fotográfica" y "el proceso fotográfico", lo cual implicaba por un lado la subjetividad del fotógrafo sobre su comprensión del objeto sobre las bases de un conoci- miento profundo del proceso fotográfico y el proceso "óptico-químico" que "verifica" la representación subjetiva, respectivamente. Cualquier modificación "con un tratamiento manual posterior" le quitaría a la técnica fotográfica su singularidad (para consultar el material, se encuentra adjuntado en el anexo). Luis relacionaba el foco en lo técnico, lo fáctico en Grete, con 'principios ciertamente estéticos que omiten conceptos tradicionalmente utilizados en el lenguaje de lo estético'. En cuanto a la manipulación posterior de la imagen, agregaba que 'tiene que ver con los procesos que se consideraban artísticos en ese período' y el ojo de Grete caracterizado por la "visión y composición" (una fotógrafa más bien de trípode). Lo comparó con el trabajo del fotógrafo francés Cartier-Bersson, en quien veía una relación con "la fugacidad del mundo", y no tanto con el aspecto fáctico. 'Las mujeres que le mostraban las fotografías de sus hijos a los soldados que liberaban París para saber si los habían visto, eso fotografiaba Cartier', me decía, no el fenómeno sino su consecuencia. Con el libro todavía abierto sobre la mesa del comedor de su casa, le pregunté sobre su fotografía preferida. 'Esta', señala cerrando el libro y mostrando la única fotografía con la que cuenta la tapa de aquella edición de Fundación Antorchas y Fundación C.E.P.P.A., 'me parece que une las dos cosas, los dos objetivos de Grete: el retrato y la artesanía', me confiesa.

\section{Consideraciones finales}

Ver la categoría de estética encarnada en prácticas o dichos particulares, funcionando en uso y acto, me permitió dar cuenta de la variabilidad y diversidad de sentidos, algo valioso de ser reconocido para lograr una comprensión más amplia de la lógica del campo. A lo largo de la presente etnografía, el campo fue entendido como una red de relaciones supuestas en tanto conceptualización, ergo recorte 
particular de la realidad en función de la presente indagación. Se trata de ir dando cuenta de un juego de relaciones de paridad, de desigualdad pero, en términos de Bourdieu, siempre en disputa. Reconocer los significados locales me enfrentó con la indexicalidad expresada en el campo y encarnada en los sujetos a quienes elegí acudir, noción, en el origen perteneciente a la lingüística, que permite dar cuenta de la importancia de la variable contextual para cada situación registrada (COULON, 1988, p. 34). Es así que tanto la categoría de estética trabajada hasta el momento como otras categorías, entre ellas la curación en arte o la idea de nación, están, a fin de cuentas, sujetas a los cambios de significación construidos socialmente y que históricamente les son otorgadas. Además, un mínimo cambio de contexto en lo cotidiano ya puede suponer una mutación de sentidos, sobre la base de la existencia de saberes socialmente compartidos; contexto a su vez identificable en mutación a lo largo de distintos momentos de una conversación (BRIGGS, 1986, p. 6).

Pensando en futuras líneas de indagación, en temáticas tocadas y descartadas para el presente trabajo, quisiera seguir profundizando en formas de representación de la nación y su diversidad étnica interna, sobre la base de la circulación y exhibición de la serie, vinculado a desarrollos anteriores en el campo del folklore y la antropología simbólica, a su vez ligado a la semiótica a partir de la consideración de la imagen como una forma de lenguaje. Quisiera asimismo ahondar en la cuestión de la marginalidad que dejé planteada sin mayores consideraciones, vinculado a los significados culturales asignados a ciertas actividades, roles o valores sociales expresados de un modo particular en el campo (DOMÍNGUEZ, 2003). Específicamente, abordarlo desde la figura de Grete como mujer en el terreno de la fotografía del siglo XX caracterizado por una fuerte presencia masculina en la actividad, sien- do ella, además, una mujer perteneciente a las primeras generaciones de mujeres europeas emancipadas de viejas normas y valores vinculados a lo que significaba ser mujer. Un último punto que creo enriquecería la reflexión sería la problematización de la categoría, como todas histórica y en transformación, de "curación" en arte. Planteadas estas posibles vías futuras, espero poder dar efectivamente continuidad a este trabajo en otra oportunidad.

\section{Bibliografía:}

ABELES, Marc. El campo y el sub-campo. En: GHASARIAN, Cristian et al: De la etnografía a la antropología reflexiva. Buenos Aires: Ediciones del Sol, 2002.

AZAROLA, Belén. (2014). Registro de observación en la Galería Vasari. Manuscrito no publicado. Buenos Aires. Universidad de Buenos Aires.

AZAROLA, Belén. Registro de observación de las imágenes. Manuscrito no publicado. Buenos Aires. Universidad de Buenos Aires.

AZAROLA, Belén. Registro de entrevista a la directora de programación y curaduría de la Fundación Proa. Manuscrito no publicado. Buenos Aires. Universidad de Buenos Aires.

AZAROLA, Belén. Registro de entrevista a Luis Priamo, especialista en la obra de Grete Stern y principal biógrafo. Manuscrito no publicado. Buenos Aires. Universidad de Buenos Aires.

BOURDIEU, Pierre. Comprender. En: BOURDIEU, Pierre. La Miseria del Mundo. Madrid: Fondo de Cultura Económica, 1999. p. 527-557.

BRIGGS, Charles. Aprendiendo a preguntar: una evaluación sociolingüística del rol de la entrevista en la investigación en Ciencias Sociales, Introducción. Learning how to ask. Cambridge: Cambridge UniversityPress. Traducción de María Elena Ordizola. Traducción de notas y corrección del manuscrito: Camila Mercado, 1986. 
COULON, Alain. La Etnometodología. Madrid: Cátedra, 1988.

DA SILVA CATELA, Ludmila ; GIORDANO, Mariana ; JELIN, Elisabeth. Fotografía e identidad. Captura por la cámara, devolución por la memoria. Buenos Aires: Nueva Trilce, 2010.

DOMINGUEZ MON, Ana. Género, ética y trabajo de campo. Perspectivas Bioéticas en las Américas. 15 bis segundo semestre, FLASCO-GIRE. Buenos Aires: Ediciones del Signo, 2003.

GADAMER, Hans-Georg. Verdad y método. Salamanca: Ediciones Sígueme, 1993.

GIORDANO, Mariana. Discurso e imagen sobre el indígena chaqueño. Buenos Aires: Al Margen, 2008.

KOHAN, Marcelo ; PRIAMO, Luis ; LENTON, Diana ; GIORDANO, Mariana. Indígenas en la Argentina, Fotografías 1860 - 1970. Buenos Aires: El Artenauta Ediciones, 2012.

MASOTTA, Carlos. Álbum postal. Buenos Aires: La Marca Editora, 2008.

PÉREZ GOLLÁN, José Antonio ; WRIGHT, Pablo ; PRIAMO, Luis ; STERN, Grete. Aborígenes del Gran Chaco. Fotografías de Grete Stern: 1958 - 1964 / seleccionadas por Luis Priamo. Buenos Aires: Fundación Antorchas ; Fundación CEPPA, 2005.

PUJADAS, Joan. El método biográfico y los géneros de la memoria. Revista de Antropología Social. 9, 127-158. Madrid. Universidad Complutense de Madrid, 2000.

ROCKWELL, Elsie. La experiencia etnográfica. Historia y cultura en los procesos educativos. Buenos Aires: Paidós, 2009.

SAUVANET, Pierre. Éléments d'esthétique. París: EllipsesÉdition, 2004.

WECHSLER, Diana. El exilio antifascista. Clement Moreau y Grete Stern. Revista de Ciencias Sociales, Buenos Aires, n. 37. 2007.

\section{Sitios web}

Estudio Heinrich-Sanguinetti. [en línea] [consulta: 17 de octubre de 2014]. Disponible en: <www.estudioheinrichsanguinetti.com/>
Fundación Proa. [en línea] [consulta: 30 de octubre de 2014]. Disponible en: <http://www.proa.org/>

Galería Vasari. [en línea] [consulta: 11 de septiembre de 2014]. Disponible en: <www.galeriavasari. com.ar/>

MALBA. [en línea] [consulta: 30 de octubre de 2014]. Disponible en: www.malba.org.ar/

\section{Recebido em 11/08/2015 Aprovado em 24/08/2015}

i Estudiante de grado de Ciencias Antropológicas. Facultad de Filosofía y Letras, U.B.A. Argentina. Contacto: belu_azarola@hotmail.com

ii Resolución 61 del 22 de julio de 1958 y resolución 164 del 21 de marzo de 1959, documentos respectivos a cada viaje (Antorchas et al., 2005, p. 36-37).

iii Desde el trabajo de Diana Wechsler sobre El exilio antifascista. ClementMoreau y GreteStern., identificamos una red de relaciones unidas en la lucha antifascista tanto desde Europa como desde Sudamérica, en la que ambos artistas y varios otros que debieron exiliarse tras el triunfo del nacional-socialismo en Alemania, se mantenían de algún u otro modo conectados.

iv El decir "Constantini" alude al MALBA, las siglas para Museo de Arte Latinoamericano de Buenos Aires, fundado en septiembre de 2001.

v MOMA, cuyas siglas originalmente se encuentran en inglés, se traduce como el Museo de Arte Moderno de Nueva York, inaugurado en Estados Unidos a fines de 1929.

vi Artista argentino nacido en 1905 y muerto en el '81.

vii Expuesto en el MALBA durante el 2014. 